\title{
Synthesis of photostable amine-reactive fluorescent dyes by post-synthetic conversion of bromide dithienothiophene derivatives
}

\author{
Giovanna Sotgiu, ${ }^{*}$ and Giovanna Barbarella \\ Istituto per la Sintesi e la Fotoreattività (ISOF), Consiglio Nazionale delle Ricerche, \\ Via Gobetti 101, I-40129 Bologna, Italy \\ sotgiu@ isof.cnr.it
}

Supporting Information

\section{Content Table}

Experimental section

Page S3

${ }^{1} \mathrm{H}$ and ${ }^{13} \mathrm{C}$ NMR spectra of compound 2

Page S7

${ }^{1} \mathrm{H}$ and ${ }^{13} \mathrm{C}$ NMR spectra of compound 3

Page S8

${ }^{1} \mathrm{H}$ and ${ }^{13} \mathrm{C}$ NMR spectra of compound 5

Page S9

${ }^{1} \mathrm{H}$ and ${ }^{13} \mathrm{C}$ NMR spectra of compound 7

Page S10

${ }^{1} \mathrm{H}$ and ${ }^{13} \mathrm{C}$ NMR spectra of compound 8

Page S11

${ }^{1} \mathrm{H}$ and ${ }^{13} \mathrm{C}$ NMR spectra of compound 9

Page S12

${ }^{1} \mathrm{H}$ and ${ }^{13} \mathrm{C}$ NMR spectra of compound $\mathbf{1 0}$

Page S13

${ }^{1} \mathrm{H}$ and ${ }^{13} \mathrm{C}$ NMR spectra of compound $\mathbf{1 1}$

Page S14

${ }^{1} \mathrm{H}$ and ${ }^{13} \mathrm{C}$ NMR spectra of compound 12

Page S15

${ }^{1} \mathrm{H}$ and ${ }^{13} \mathrm{C}$ NMR spectra of compound $\mathbf{1 3}$

Page S16

${ }^{1} \mathrm{H}$ and ${ }^{13} \mathrm{C}$ NMR spectra of compound $\mathbf{1 4}$

Page S17 
${ }^{1} \mathrm{H}$ and ${ }^{13} \mathrm{C}$ NMR spectra of compound 15

Page S18

${ }^{1} \mathrm{H}$ and ${ }^{13} \mathrm{C}$ NMR spectra of compound 16

Page S19

${ }^{1} \mathrm{H}$ and ${ }^{13} \mathrm{C}$ NMR spectra of compound 18

Page S20

${ }^{1} \mathrm{H}$ NMR spectra of compound 4 and 6

Page S21

${ }^{1} \mathrm{H}$ NMR spectra of compound $\mathbf{1 7}$

Page S22 


\section{Experimental section}

General procedure for the preparation of the isothiocyanate. A $5 \mathrm{~mL}$ conical vial was charged with the bromo-butyl derivate ( 1 equiv.) and sodium thiocyanate ( 1 equiv.) in distilled acetone (4 $\mathrm{mL}$ ). The mixture was vigorously stirred at $200{ }^{\circ} \mathrm{C}$ for $2 \mathrm{~h} .{ }^{15}$ After cooling to room temperature, the crude material was filtered through a silica gel plug to remove the excess sodium salt. The solvent was removed by rotary evaporation, and the residue was purified by different techniques as indicated for each compound.

\section{1-(4,4-dioxo-dithieno[3,2-b;2',3'-d]thiophen-2-yl)-4-isothiocyanato-butan-1-one (11).}

Purified by several washings with warm pentane yielding $76.8 \mathrm{mg}(60 \%)$ of a yellow solid: Anal. Calcd for $\mathrm{C}_{13} \mathrm{H}_{9} \mathrm{NO}_{3} \mathrm{~S}_{4} \mathrm{C}, 43.92 ; \mathrm{H}, 2.55$. Found $\mathrm{C}, 44.11 ; \mathrm{H}, 2.77 ; \mathrm{mp} 157{ }^{\circ} \mathrm{C}$; MS m/e $355\left(\mathrm{M}^{++}\right)$; FTIR (neat) $v_{\mathrm{SO} 2} 1302,1139 \mathrm{~cm}^{-1}, v_{\mathrm{CO}} 1661 \mathrm{~cm}^{-1}, v_{\mathrm{NCS}} 2152 \mathrm{~cm}^{-1} ; \lambda_{\max }\left(\mathrm{CH}_{2} \mathrm{Cl}_{2}\right)=374 \mathrm{~nm} ; \lambda_{\text {em }}$ $\left(\mathrm{CH}_{2} \mathrm{Cl}_{2}\right)=454 \mathrm{~nm} ; \varepsilon\left(\mathrm{CH}_{2} \mathrm{Cl}_{2}\right)=13947 \mathrm{M}^{-1} * \mathrm{~cm}^{-1} ;{ }^{1} \mathrm{H}$ NMR $\left(\mathrm{CDCl}_{3}\right) \delta 7.761(\mathrm{~s}, 1 \mathrm{H}), 7.537\left(\mathrm{~d},{ }^{3} J=5.2\right.$ $\mathrm{Hz}, 1 \mathrm{H}), 7.291\left(\mathrm{~d},{ }^{3} \mathrm{~J}=5.2 \mathrm{~Hz}, 1 \mathrm{H}\right), 3.094(\mathrm{~m}, 4 \mathrm{H}), 2.307(\mathrm{~m}, 2 \mathrm{H}) ;{ }^{13} \mathrm{C} \mathrm{NMR}\left(\mathrm{CDCl}_{3}\right) \delta 190.4,147.0$, $145.1,143.3,142.2,135.0,132.6,123.7,120.7,35.9,33.1,23.9$.

\section{4-isothiocyanato-1-[6-(5-octylthio-thiophen-2-yl)-4,4-dioxo-dithieno[3,2-b;2',3'-d]-thiophen-2- yl]-butan-1-one (12).}

Purified by several washings with hexane giving $14.1 \mathrm{mg}$ (64\% yield) of an orange solid: Anal. Calcd for $\mathrm{C}_{25} \mathrm{H}_{27} \mathrm{NO}_{3} \mathrm{~S}_{6} \mathrm{C}, 51.60 ; \mathrm{H}, 4$.68. Found $\mathrm{C}, 51.81 ; \mathrm{H}, 4.96 ; \mathrm{mp} 155^{\circ} \mathrm{C} ; \mathrm{MS} m / e 581\left(\mathrm{M}^{-+}\right)$; FTIR (neat) $v_{\mathrm{SO} 2} 1305,1140 \mathrm{~cm}^{-1}, v_{\mathrm{CO}} 1656 \mathrm{~cm}^{-1}, v_{\mathrm{NCS}} 2192 \mathrm{~cm}^{-1} ; \lambda_{\max }\left(\mathrm{CH}_{2} \mathrm{Cl}_{2}\right)=440 \mathrm{~nm} ; \lambda_{\text {em }}$ $\left(\mathrm{CH}_{2} \mathrm{Cl}_{2}\right)=600 \mathrm{~nm} ; \varepsilon\left(\mathrm{CH}_{2} \mathrm{Cl}_{2}\right)=14187 \mathrm{M}^{-1} * \mathrm{~cm}^{-1} ;{ }^{1} \mathrm{H} \mathrm{NMR}\left(\mathrm{CDCl}_{3}\right) \delta 7.760(\mathrm{~s}, 1 \mathrm{H}), 7.247(\mathrm{~s}, 1 \mathrm{H})$, $7.136\left(\mathrm{~d},{ }^{3} \mathrm{~J}=4.0 \mathrm{~Hz}, 1 \mathrm{H}\right), 7.028\left(\mathrm{~d},{ }^{3} \mathrm{~J}=3.6 \mathrm{~Hz}, 1 \mathrm{H}\right), 3.111\left(\mathrm{t},{ }^{3} \mathrm{~J}=6.8 \mathrm{~Hz}, 4 \mathrm{H}\right), 2.870\left(\mathrm{t},{ }^{3} \mathrm{~J}=7.6 \mathrm{~Hz}\right.$, 2H), $2.317(\mathrm{~m}, 2 \mathrm{H}), 1.724(\mathrm{~m}, 2 \mathrm{H}), 1.435(\mathrm{~m}, 2 \mathrm{H}), 1.249(\mathrm{bs}, 8 \mathrm{H}), 0.877(\mathrm{t}, 6.4 \mathrm{~Hz}, 3 \mathrm{H}) ;{ }^{13} \mathrm{C} \mathrm{NMR}$ $\left(\mathrm{CDCl}_{3}\right) \delta 190.3,146.8,145.6,145.1,142.4,142.2,139.0,136.6,133.2,131.7,126.1,123.6,115.7$ $111.7,38.7,35.8,33.1,31.8,29.4,29.14,29.06,28.4,23.9,22.6,14.1$. 


\section{2-(4-isothiocyanato-butyl)-dithieno[3,2-b;2',3'-d]thiophene-4,4-dioxide (13).}

Purified by crystallization from toluene/pentane to provide $40 \mathrm{mg}$ ( $85 \%$ yield) of the title compound as a ochre yellow solid: Anal. Calcd for $\mathrm{C}_{13} \mathrm{H}_{11} \mathrm{NO}_{2} \mathrm{~S}_{4}$ : C, 45.72; H, 3.25. Found C, 45.91; H, 3.51; mp $140{ }^{\circ} \mathrm{C}$; MS m/e $341\left(\mathrm{M}^{++}\right)$; FTIR (neat) $v_{\mathrm{SO} 2} 1306,1139 \mathrm{~cm}^{-1} ; v_{\mathrm{NCS}} 2149 \mathrm{~cm}^{-1} ; \lambda_{\max }$ $\left(\mathrm{CH}_{2} \mathrm{Cl}_{2}\right)=361 \mathrm{~nm} ; \lambda_{\text {em }}\left(\mathrm{CH}_{2} \mathrm{Cl}_{2}\right)=463 \mathrm{~nm} ; \varepsilon\left(\mathrm{CH}_{2} \mathrm{Cl}_{2}\right)=8523 \mathrm{M}^{-1} * \mathrm{~cm}^{-1} ;{ }^{1} \mathrm{H} \mathrm{NMR}\left(\mathrm{CDCl}_{3}\right) \delta 7.315$ $\left(\mathrm{d},{ }^{3} J=5.2 \mathrm{~Hz}, 1 \mathrm{H}\right), 7.196\left(\mathrm{~d},{ }^{3} J=5.2 \mathrm{~Hz}, 1 \mathrm{H}\right), 6.932\left(\mathrm{t},{ }^{4} J=1.2 \mathrm{~Hz}, 1 \mathrm{H}\right), 2.980\left(\mathrm{t},{ }^{3} J=6.8 \mathrm{~Hz}, 2 \mathrm{H}\right)$, $2.894\left(\mathrm{t},{ }^{3} \mathrm{~J}=7.6 \mathrm{~Hz}, 2 \mathrm{H}\right), 1.893(\mathrm{~m}, 4 \mathrm{H}) ;{ }^{13} \mathrm{C} \mathrm{NMR}\left(\mathrm{CDCl}_{3}\right) \delta 149.9,142.6,142.1,136.4,133.5$, $129.1,120.2,117.3,112.0,33.5,29.9,29.5,29.0$.

\section{2-(4-isothiocyanato-butyl)-6-(5-octylthio-thiophen-2-yl)-dithieno[3,2-b;2',3'-d]thiophene-4,4-} dioxide (15).

Purified by crystallization from isopropanol giving $54 \mathrm{mg}$ (92\% yield) of an orange solid: Anal. Calcd for $\mathrm{C}_{25} \mathrm{H}_{29} \mathrm{NO}_{2} \mathrm{~S}_{6} \mathrm{C}, 52.87 ; \mathrm{H}, 5.15$. Found $\mathrm{C}, 53.07 ; \mathrm{H}, 5.18 ; \mathrm{mp} 102{ }^{\circ} \mathrm{C} ; \mathrm{MS}$ m/e $567\left(\mathrm{M}^{++}\right)$; FTIR (neat) $v_{\mathrm{SO} 2} 1302,1134 \mathrm{~cm}^{-1}, v_{\mathrm{NCS}} 2154 \mathrm{~cm}^{-1} ; \lambda_{\max }\left(\mathrm{CH}_{2} \mathrm{Cl}_{2}\right)=418 \mathrm{~nm} ; \lambda_{\mathrm{em}}\left(\mathrm{CH}_{2} \mathrm{Cl}_{2}\right)=552 \mathrm{~nm} ; \varepsilon$ $\left(\mathrm{CH}_{2} \mathrm{Cl}_{2}\right)=28417 \mathrm{M}^{-1} * \mathrm{~cm}^{-1} ;{ }^{1} \mathrm{H}$ NMR $\left(\mathrm{CDCl}_{3}\right) \delta 7.176(\mathrm{~s}, 1 \mathrm{H}), 7.054\left(\mathrm{~d},{ }^{3} J=4.0 \mathrm{~Hz}, 1 \mathrm{H}\right), 7.004(\mathrm{~d}$,

$\left.{ }^{3} J=3.6 \mathrm{~Hz}, 1 \mathrm{H}\right), 6.943\left(\mathrm{t},{ }^{4} J=1.2 \mathrm{~Hz}, 1 \mathrm{H}\right), 2.988\left(\mathrm{t},{ }^{3} J=6.8 \mathrm{~Hz}, 2 \mathrm{H}\right), 2.905\left(\mathrm{t},{ }^{3} J=7.6 \mathrm{~Hz}, 2 \mathrm{H}\right), 2.842$ $\left(\mathrm{t},{ }^{3} J=7.2 \mathrm{~Hz}, 2 \mathrm{H}\right), 1.913(\mathrm{~m}, 4 \mathrm{H}), 1.642(\mathrm{~m}, 2 \mathrm{H}), 1.400(\mathrm{~m}, 2 \mathrm{H}), 1.268$ (bs, 8H), 0.875 (t, $6.8 \mathrm{~Hz}$, $3 \mathrm{H}) ;{ }^{13} \mathrm{C} \mathrm{NMR}\left(\mathrm{CDCl}_{3}\right) \delta 150.1,142.5,141.8,141.3,137.5,137.3,133.6,133.6,133.5,125.1$, $117.4,115.6,111.9,38.8,33.5,31.7,30.0,29.6,29.4,29.12,29.08,29.05,28.4,22.6,14.1$.

\section{4-(4,4-dioxo-dithieno[3,2-b;2',3'-d]thiophen-2-yl)-butan-1-ol (14).}

A solution of the compound 2-(4-bromo-butyl)-dithieno[3,2-b;2',3'-d]thiophene-4,4-dioxide (8) (154 mg, $0.424 \mathrm{mmol})$ in $15 \%(\mathrm{v} / \mathrm{v})$ aqueous NMP $(2.5 \mathrm{~mL})$ was heated at $130{ }^{\circ} \mathrm{C}$ and the reaction progress monitored by TLC (diethyl ether/dichloromethane/ethyl acetate 6:3:1). After $24 \mathrm{~h}$ the mixture was cooled, diluted with water and extracted with ether. The organic phase was washed with water, dried $\left(\mathrm{Na}_{2} \mathrm{SO}_{4}\right)$ and concentrated using a rotary evaporator. Bulb-to-bulb distillation 
gave $114 \mathrm{mg}$ (89\% yield) of the title product as a yellow solid: Anal. Calcd for $\mathrm{C}_{12} \mathrm{H}_{12} \mathrm{O}_{3} \mathrm{~S}_{3} \mathrm{C}$, 47.98; H, 4.03. Found C, 48.17; H, 4.30; mp $115{ }^{\circ} \mathrm{C}$; MS m/e $300\left(\mathrm{M}^{+}\right)$; FTIR (neat) $v_{\mathrm{SO} 2} 1304$, $1135 \mathrm{~cm}^{-1} ; \lambda_{\max }\left(\mathrm{CH}_{2} \mathrm{Cl}_{2}\right)=363 \mathrm{~nm} ; \lambda_{\mathrm{em}}\left(\mathrm{CH}_{2} \mathrm{Cl}_{2}\right)=457 \mathrm{~nm} ; \varepsilon\left(\mathrm{CH}_{2} \mathrm{Cl}_{2}\right)=9878 \mathrm{M}^{-1} * \mathrm{~cm}^{-1} ;{ }^{1} \mathrm{H} \mathrm{NMR}$

$\left(\mathrm{CDCl}_{3}\right) \delta 7.29\left(\mathrm{~d},{ }^{3} J=5.2 \mathrm{~Hz}, 1 \mathrm{H}\right), 7.182\left(\mathrm{~d},{ }^{3} J=5.2 \mathrm{~Hz}, 1 \mathrm{H}\right), 6.912\left(\mathrm{t},{ }^{4} J=0.8 \mathrm{~Hz}, 1 \mathrm{H}\right), 3.674(\mathrm{t}$, $\left.{ }^{3} J=6.4 \mathrm{~Hz}, 2 \mathrm{H}\right), 2.863\left(\mathrm{t},{ }^{3} \mathrm{~J}=7.6 \mathrm{~Hz}, 2 \mathrm{H}\right), 1.780(\mathrm{~m}, 2 \mathrm{H}) ; 1.659(\mathrm{~m}, 2 \mathrm{H}) ;{ }^{13} \mathrm{C} \mathrm{NMR}\left(\mathrm{CDCl}_{3}\right) \delta 151.3$, $142.5,142.0,136.6,133.1,128.8,120.1,117.0,62.2,31.7,30.3,27.6$.

\section{5-[6-(5-octylthio-thiophen-2-yl)-4,4-dioxo-dithieno[3,2-b;2',3'-d]thiophen-2-yl]-pentanenitrile} (16).

Trimethylsilyl cyanide $(10 \mu \mathrm{L}, 0.06 \mathrm{mmol})$ and tetrabutyl ammonium fluoride TBAF (60 $\mu \mathrm{L}, 0.06$ mmol) were added to a stirred solution of 2-(4-bromo-butyl)-6-(5-octylthio-thiophen-2-yl)dithieno[3,2-b;2',3'-d] thiophene-4,4-dioxide (10) $(23 \mathrm{mg}, 0.04 \mathrm{mmol})$ in $5 \mathrm{~mL}$ of acetonitrile under an atmosphere of nitrogen. The mixture was stirred at room temperature overnight. The solvent was removed by rotary evaporation, and the remaining residue was purified by flash chromatography (silica gel; petroleum ether/diethyl ether/dichloromethane 6:3:1) giving $20 \mathrm{mg}$ of the title compound as a yellow solid $\left(93 \%\right.$ yield): $\mathrm{mp} 153^{\circ} \mathrm{C}$; MS m/e $535\left(\mathrm{M}^{*+}\right) ;{ }^{1} \mathrm{H} \mathrm{NMR}\left(\mathrm{CDCl}_{3}\right) \delta 7.178(\mathrm{~s}, 1 \mathrm{H})$, $7.056\left(\mathrm{~d},{ }^{3} J=3.6 \mathrm{~Hz}, 1 \mathrm{H}\right), 7.006\left(\mathrm{~d},{ }^{3} J=3.6 \mathrm{~Hz}, 1 \mathrm{H}\right), 6.94(\mathrm{~s}, 1 \mathrm{H}), 2.906\left(\mathrm{t},{ }^{3} J=7.2 \mathrm{~Hz}, 2 \mathrm{H}\right), 2.845$ (t, $\left.{ }^{3} J=7.2 \mathrm{~Hz}, 2 \mathrm{H}\right), 2.408\left(\mathrm{t},{ }^{3} J=7.2 \mathrm{~Hz}, 2 \mathrm{H}\right), 1.876(\mathrm{~m}, 2 \mathrm{H}), 1.761(\mathrm{~m}, 2 \mathrm{H}), 1.646(\mathrm{~m}, 2 \mathrm{H}), 1.271$ (m, $10 \mathrm{H}), 0.877(\mathrm{t}, 6.8 \mathrm{~Hz}, 3 \mathrm{H}) ;{ }^{13} \mathrm{C} \mathrm{NMR}\left(\mathrm{CDCl}_{3}\right) \delta 150.0,142.6,141.9,141.4,137.5,137.4,133.6$, $133.4,125.2,119.1,117.4,115.6,38.8,31.7,30.2,29.47,29.38,29.13,29.05,28.4,24.493,22.6$, 17.0, 14.1 .

\section{5-[6-(5-octylthio-thiophen-2-yl)-4,4-dioxo-dithieno[3,2-b;2',3'-d]thiophen-2-yl]-pentananoic} acid (17).

A solution containing $19 \mathrm{mg}(0.035 \mathrm{mmol})$ of nitrile derivative 16 and $56 \mathrm{mg}$ of $\mathrm{KOH}$ in $4 \mathrm{~mL}$ of a 2.5:1 ethanol-water mixture was heated at reflux for $36 \mathrm{~h}$. At the end of this time the solution was 
allowed to cool to $\mathrm{rt}$ and the ethanol removed under reduced pressure. The solution was acidified with $\mathrm{HCl}$ and extracted with $\mathrm{CH}_{2} \mathrm{Cl}_{2}$. The organic phase was washed with water, dried $\left(\mathrm{Na}_{2} \mathrm{SO}_{4}\right)$, and the solvent evaporated. The residue was crystallized from diethyl ether to give compound (17) as a yellow solid (14 mg, 74\% yield): $\mathrm{mp} 172-173^{\circ} \mathrm{C}$; $\mathrm{MS} m / e 554\left(\mathrm{M}^{\cdot+}\right) ;{ }^{1} \mathrm{H} \mathrm{NMR}\left(\mathrm{CDCl}_{3}\right) \delta 7.172$ (s, 1H), $7.050\left(\mathrm{~d},{ }^{3} \mathrm{~J}=3.6 \mathrm{~Hz}, 1 \mathrm{H}\right), 7.004\left(\mathrm{~d},{ }^{3} \mathrm{~J}=3.6 \mathrm{~Hz}, 1 \mathrm{H}\right), 6.931(\mathrm{~s}, 1 \mathrm{H}), 2.842(\mathrm{~m}, 4 \mathrm{H}), 1.752(\mathrm{~m}$, 4H), 1.645 (m, 4H), $1.270(\mathrm{~m}, 10 \mathrm{H}), 0.877$ (m, 3H).

\section{5-[6-(5-octylthio-thiophen-2-yl)-4,4-dioxo-dithieno[3,2-b;2',3'-d]thiophen-2-yl]-pentananoic} acid 2,5-dioxo-pyrrolidin-1-yl ester (18).

A mixture of carboxylic acid derivative 17 (14 mg, $0.025 \mathrm{mmol}), N$-hydroxysuccinimide (2.93 mg, $0.025 \mathrm{mmol})$ and $N, N$-dicyclohexylcarbodiimide $(6.76 \mathrm{mg}, 0.032 \mathrm{mmol})$ in $2 \mathrm{~mL}$ of dry THF was stirred overnight at rt. The solid was filtered off and washed with dry THF, and the filtrate evaporated under vacuum. The crude product was purified by recrystallization from methylene chloride/hexane giving $12 \mathrm{mg}$ of yellow solid (74\% yield): Anal. Calcd for $\mathrm{C}_{29} \mathrm{H}_{33} \mathrm{NO}_{6} \mathrm{~S}_{5} \mathrm{C}, 53.43$; $\mathrm{H}$, 5.10. Found C, 53.64; H, 5.3; mp 187-188 ${ }^{\circ} \mathrm{C}$; MS $651 \mathrm{~m} / \mathrm{e}\left(\mathrm{M}^{*+}\right) ; \lambda_{\max }\left(\mathrm{CH}_{2} \mathrm{Cl}_{2}\right)=415 \mathrm{~nm} ; \lambda_{\mathrm{em}}$ $\left(\mathrm{CH}_{2} \mathrm{Cl}_{2}\right)=547 \mathrm{~nm} ;{ }^{1} \mathrm{H}$ NMR $\left(\mathrm{CDCl}_{3}\right) \delta 7.177(\mathrm{~s}, 1 \mathrm{H}), 7.056\left(\mathrm{~d},{ }^{3} \mathrm{~J}=4 \mathrm{~Hz}, 1 \mathrm{H}\right), 7.012\left(\mathrm{~d},{ }^{3} \mathrm{~J}=4 \mathrm{~Hz}\right.$, 1H), $6.965(\mathrm{~s}, 1 \mathrm{H}), 3.437(\mathrm{~m}, 4 \mathrm{H}), 2.853(\mathrm{~m}, 4 \mathrm{H}), 1.883(\mathrm{~m}, 4 \mathrm{H}), 1.659(\mathrm{~m}, 4 \mathrm{H}), 1.329(\mathrm{~m}, 10 \mathrm{H})$, $0.880(\mathrm{t}, 3 \mathrm{H}) ;{ }^{13} \mathrm{C} \mathrm{NMR}\left(\mathrm{CDCl}_{3}\right) \delta 169.1,168.2,150.7,142.5,141.8,141.1,137.6,137.2,133.5$, $133.4,117.3,115.6,38.8,33.8,31.8,30.6,30.2,29.4,29.1,28.4,25.6,24.9,23.8,22.6,14.1$. 


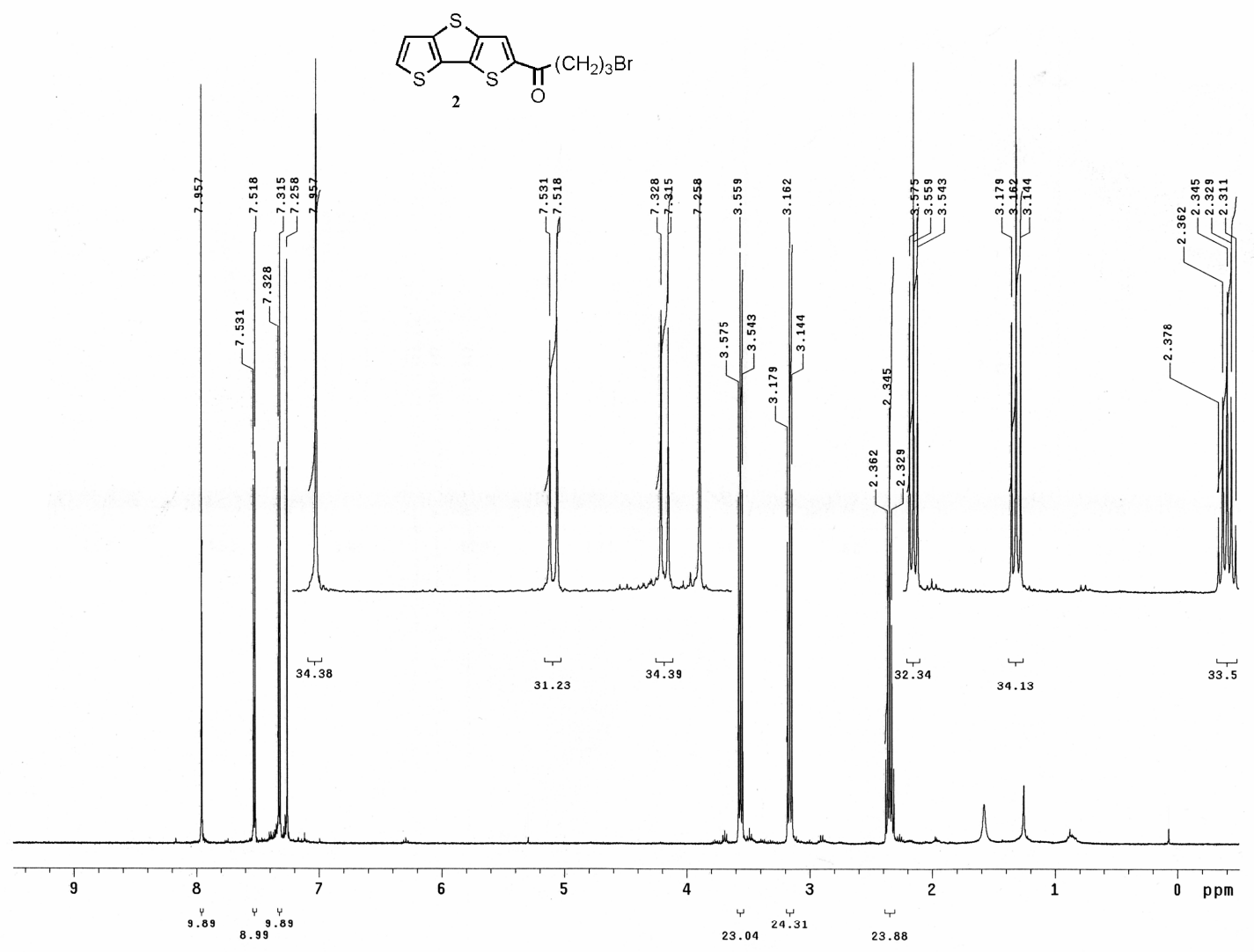

L

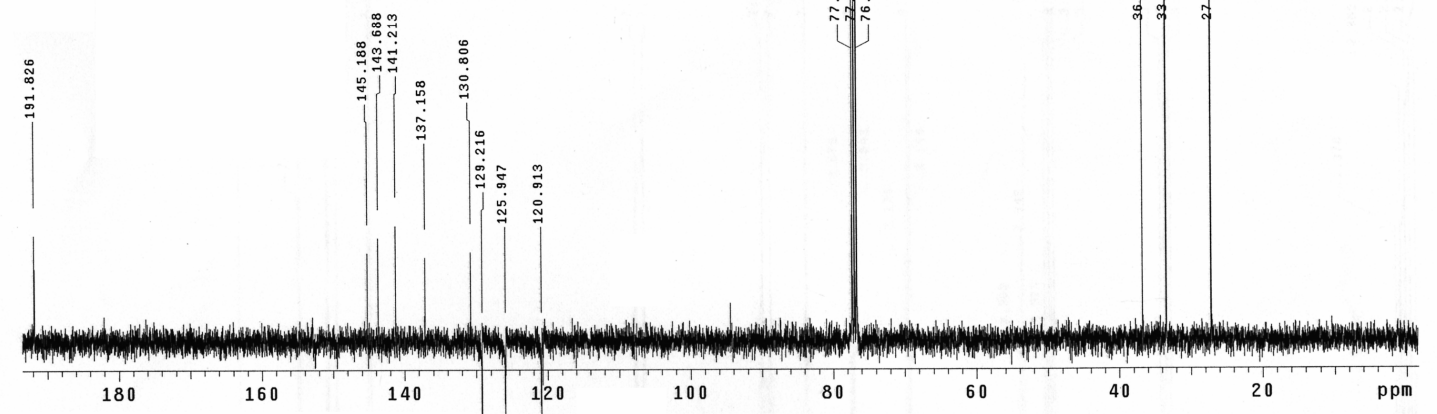



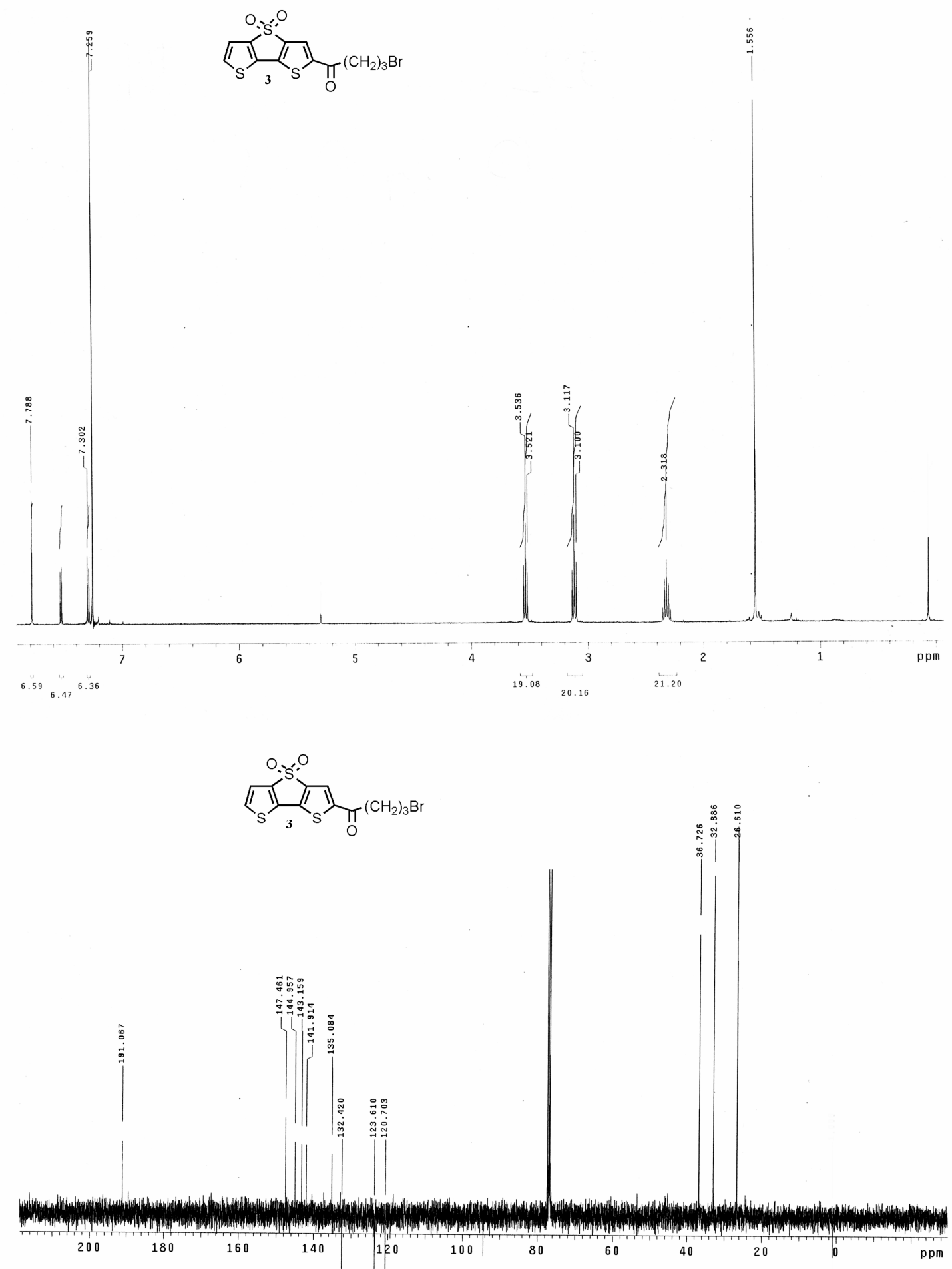

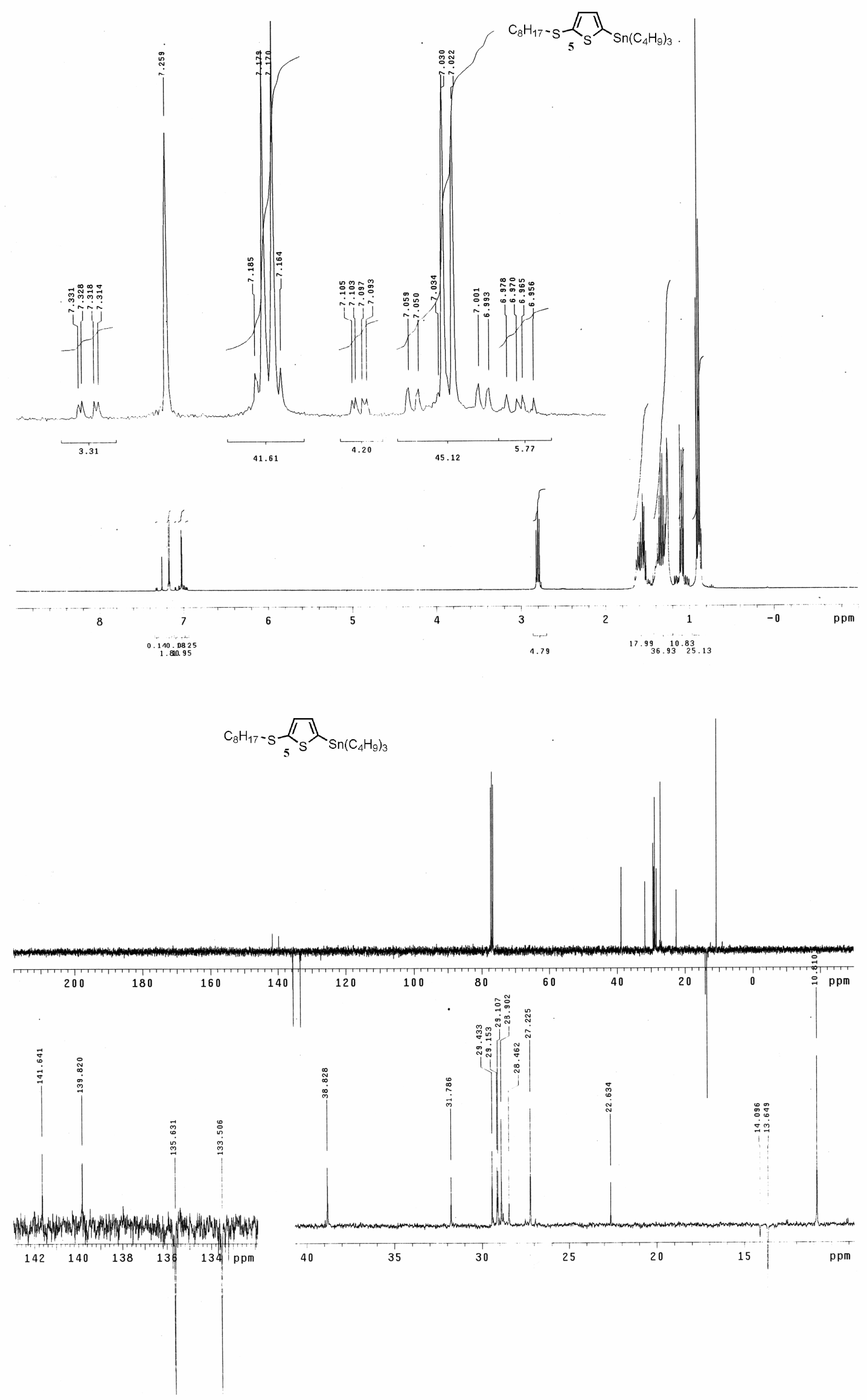

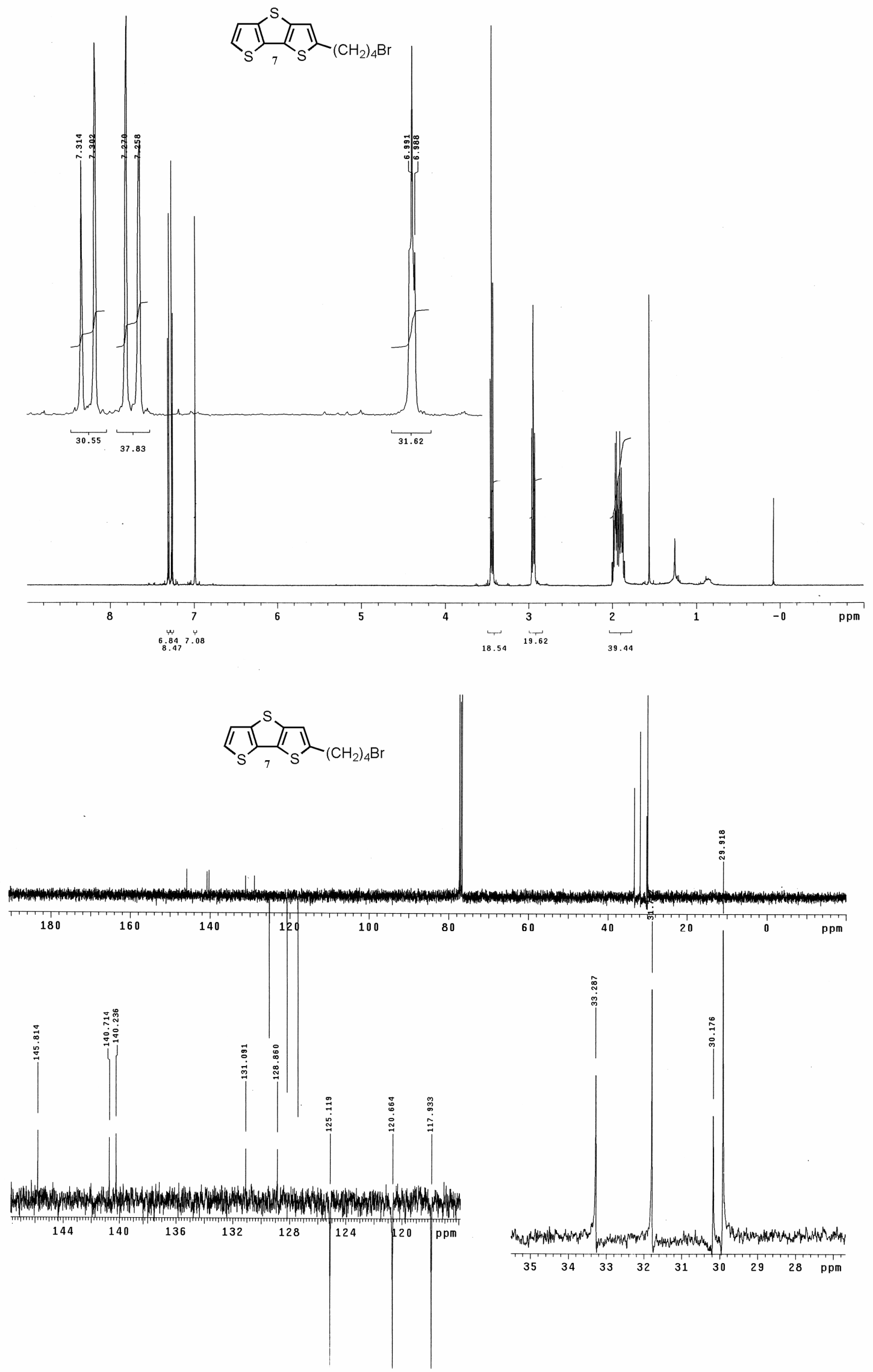

S10 

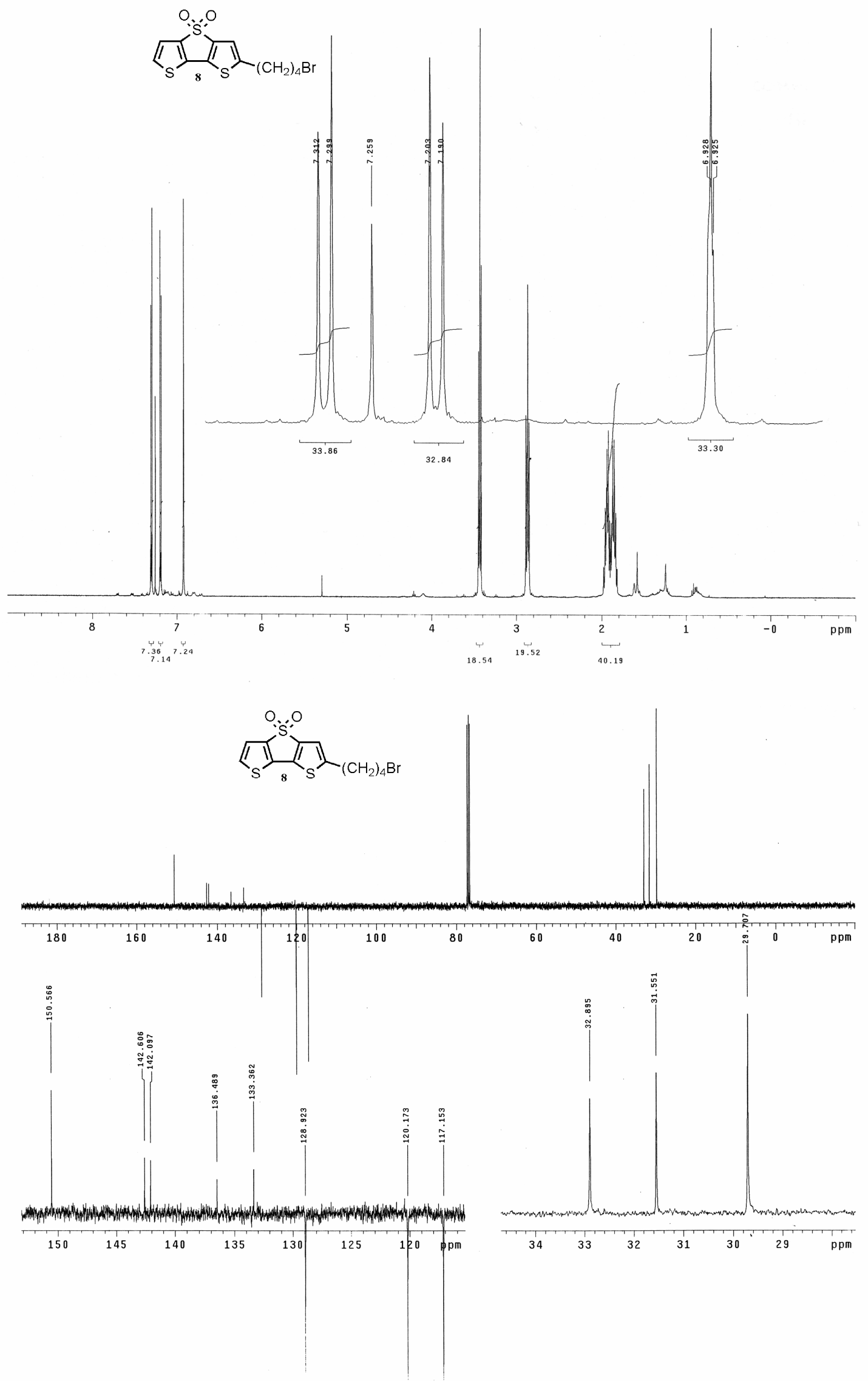

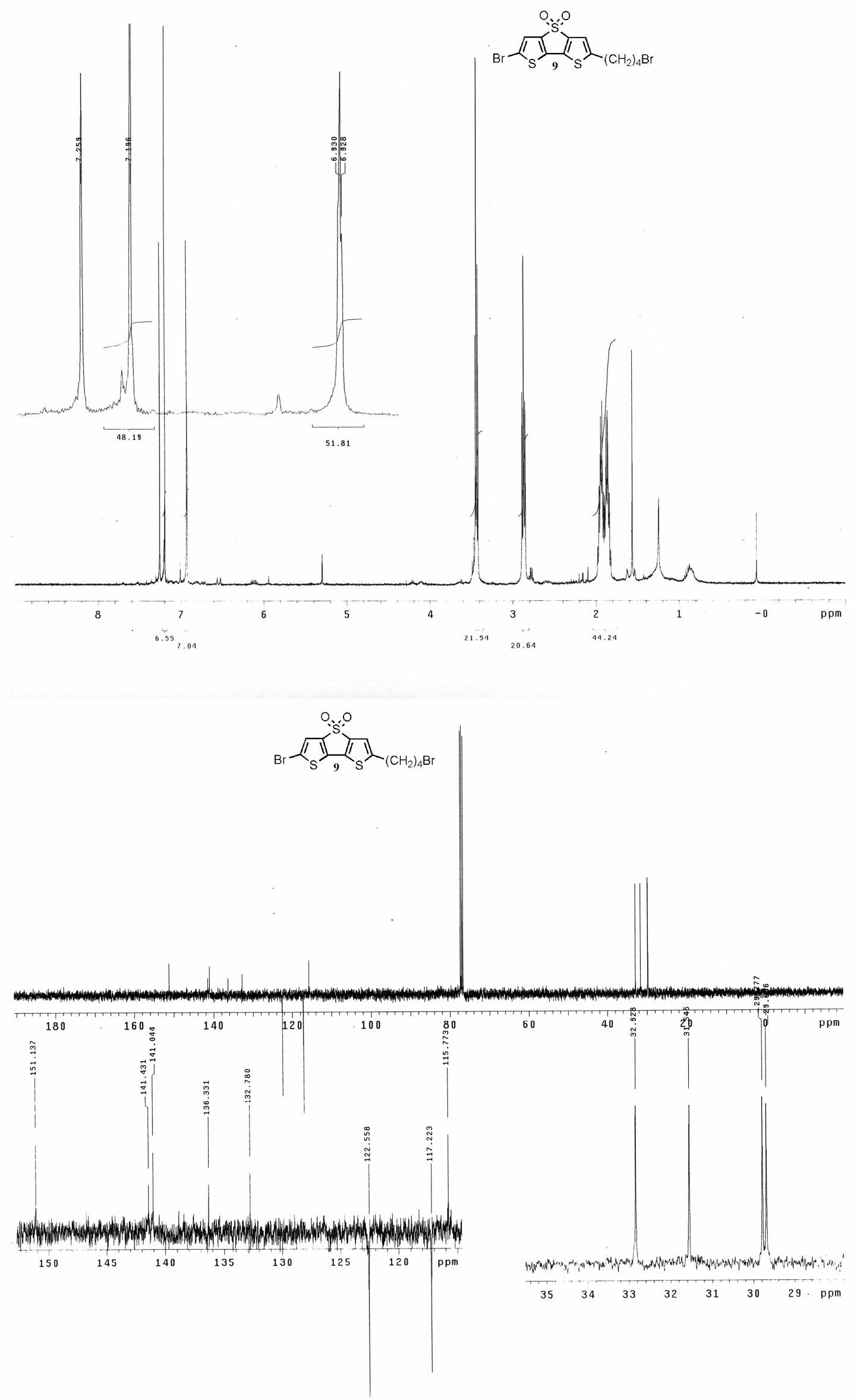

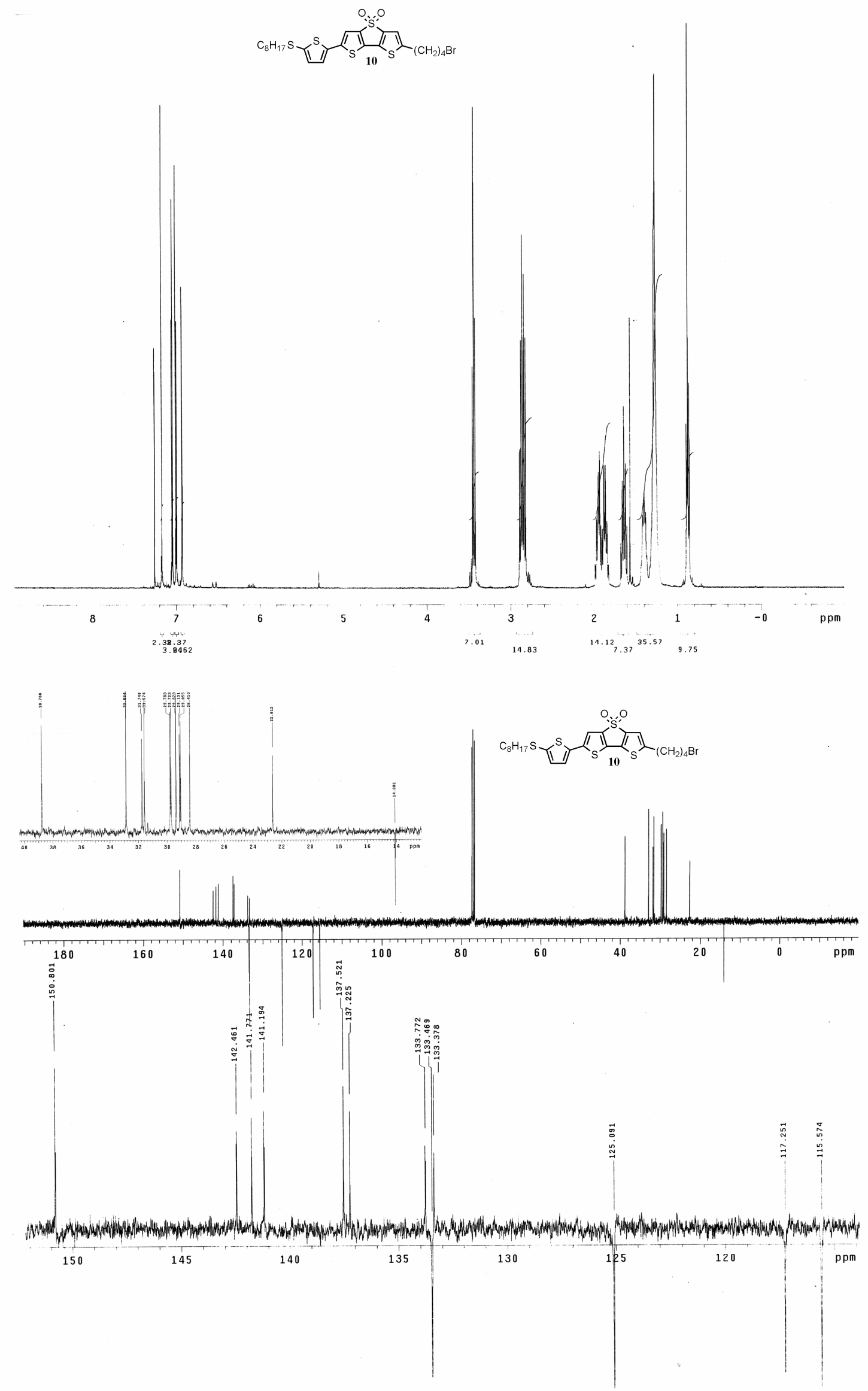

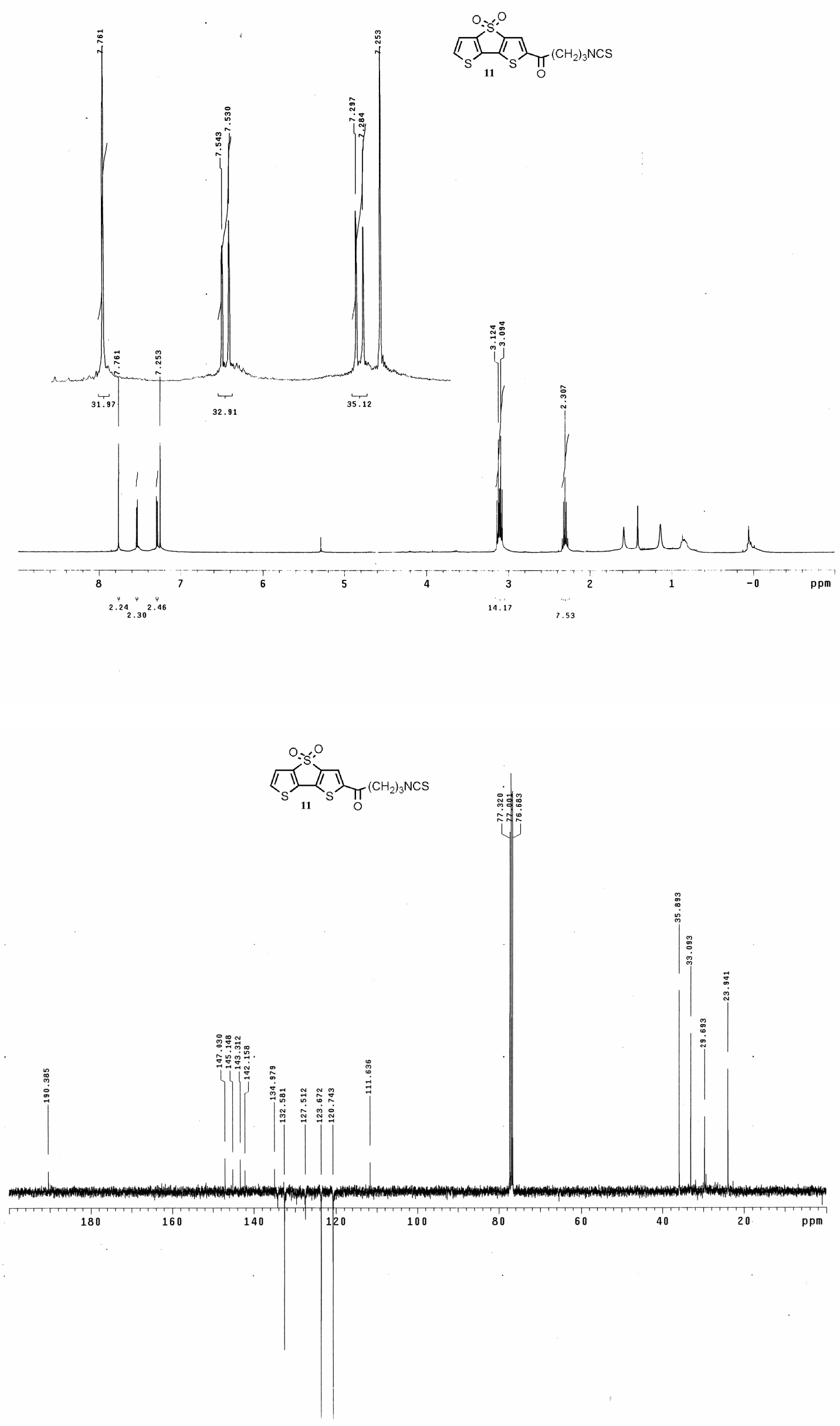

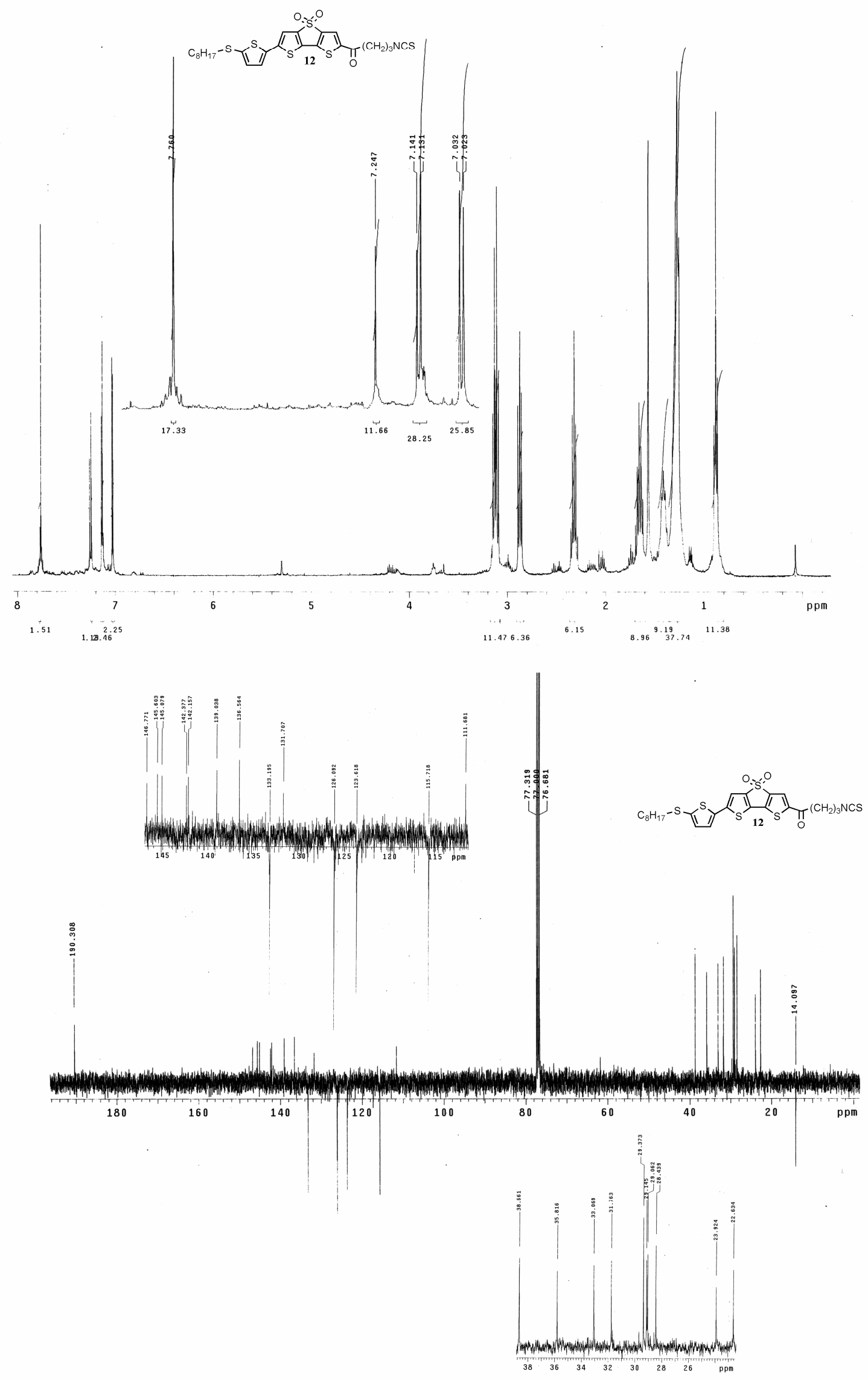

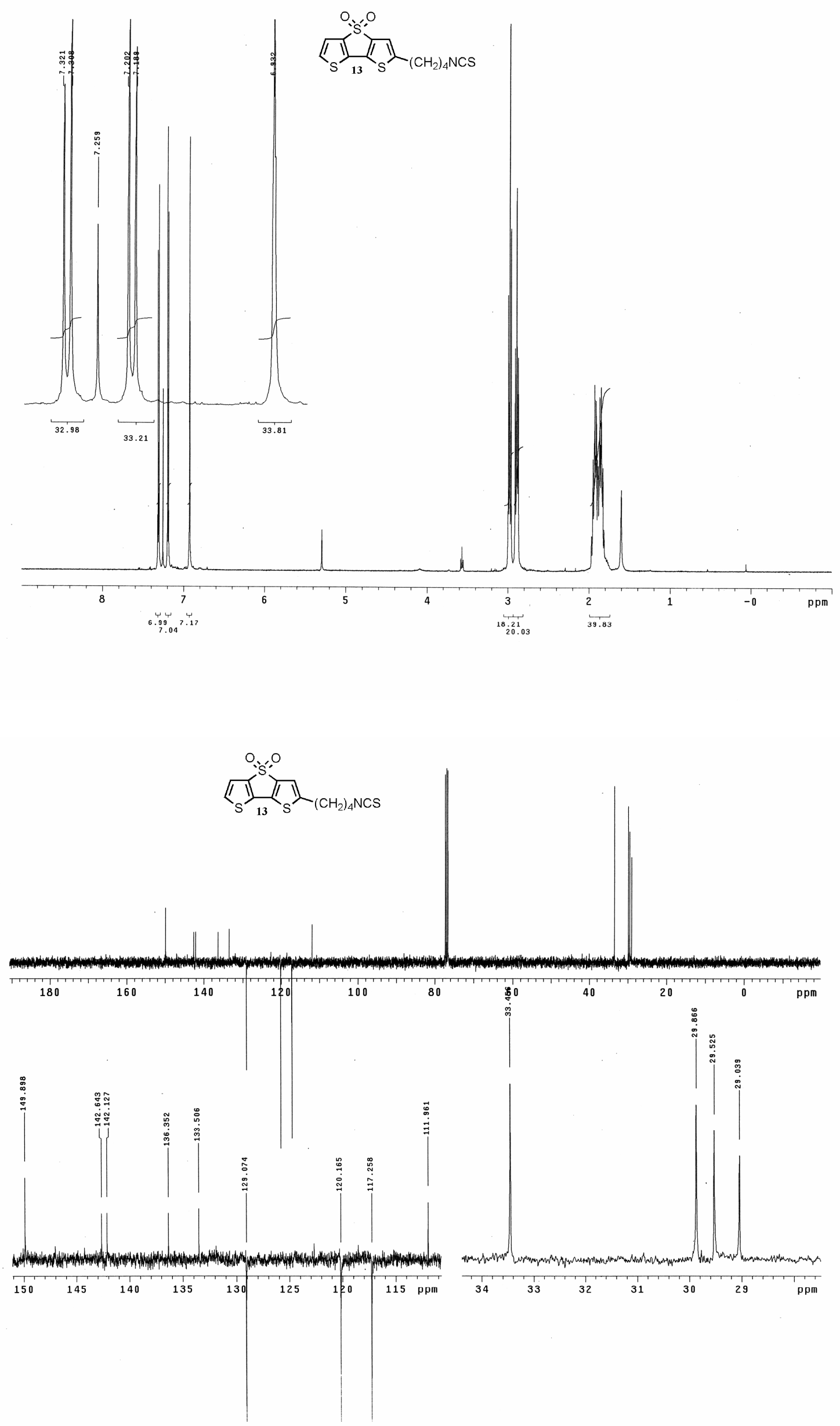

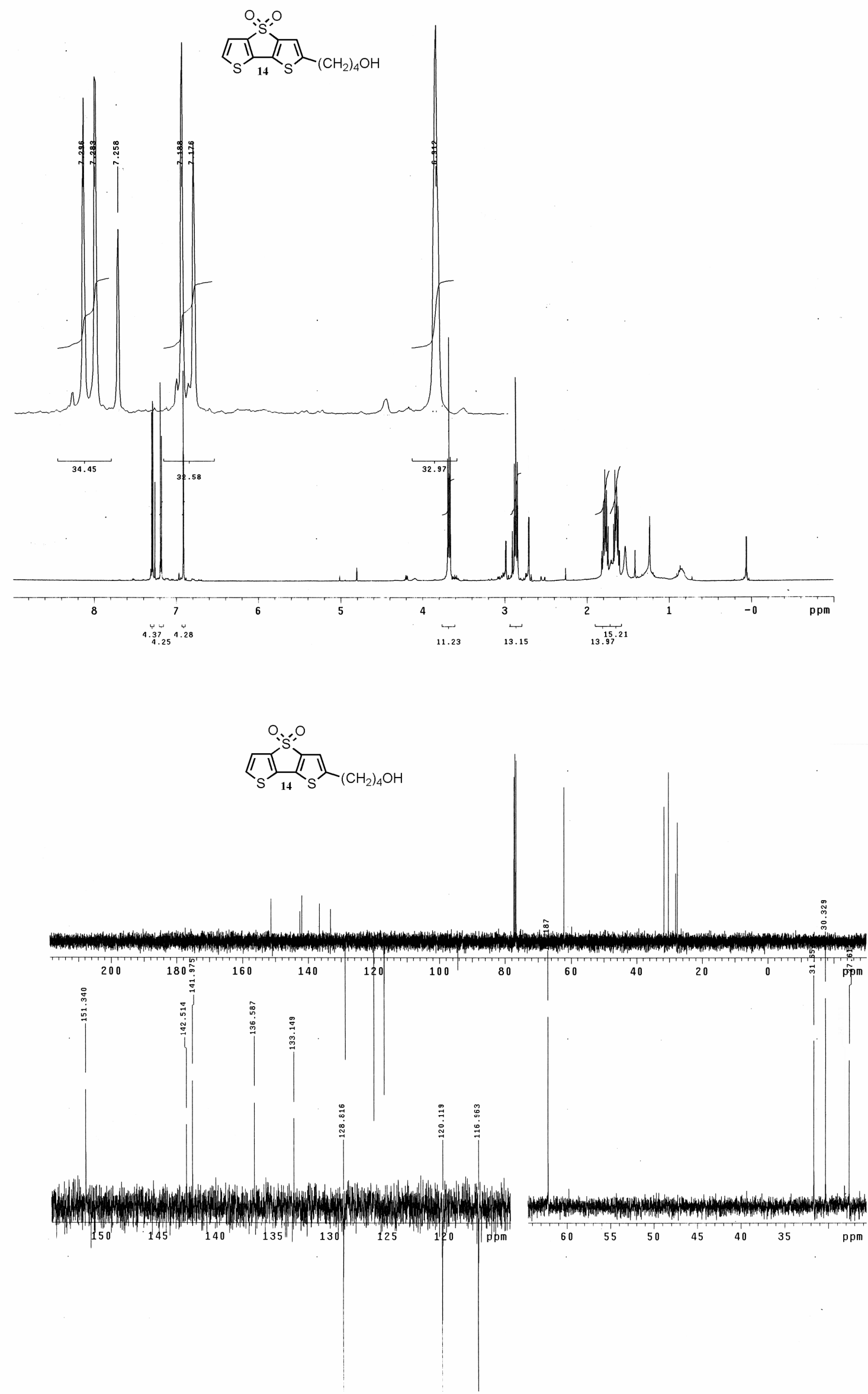

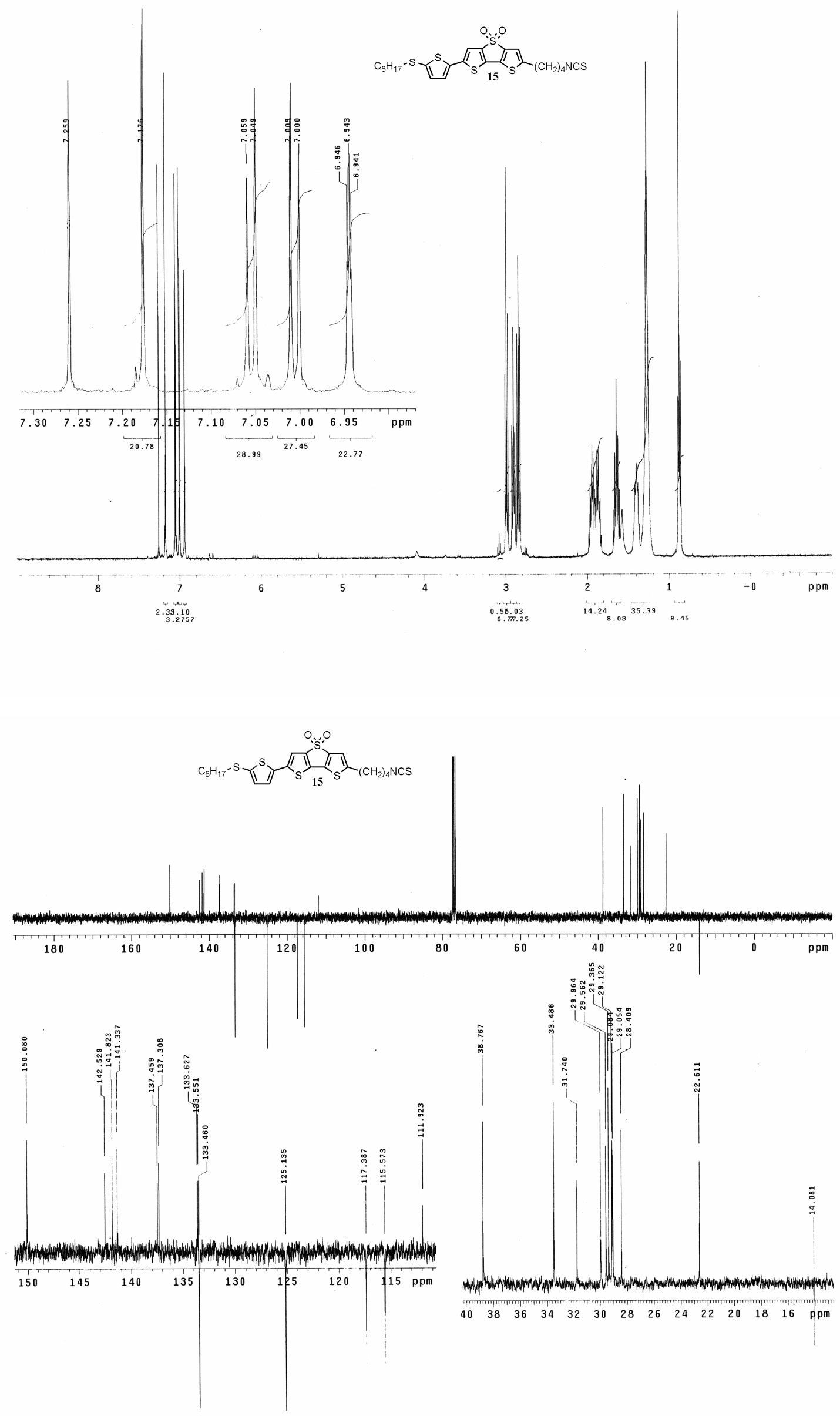

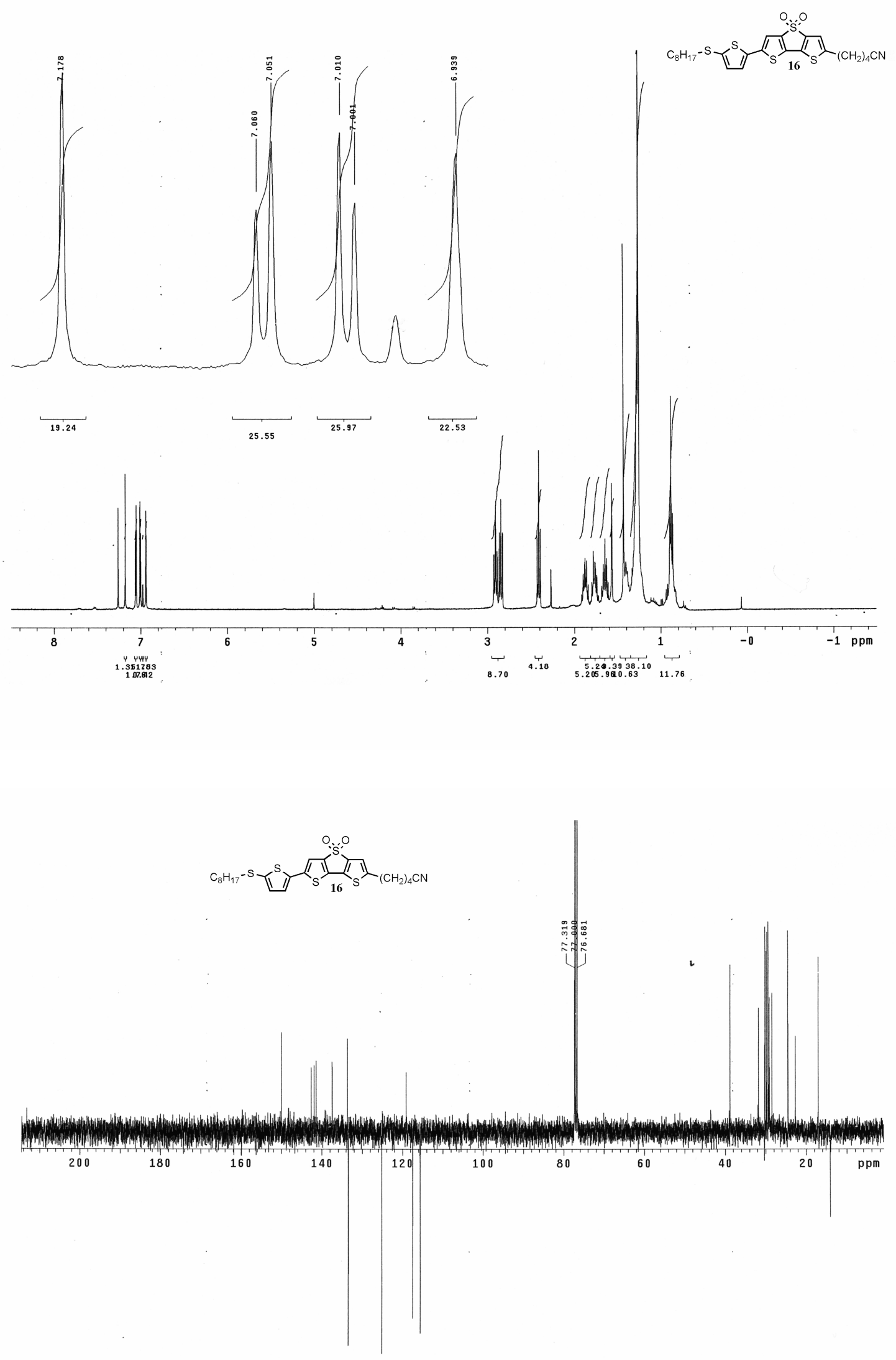

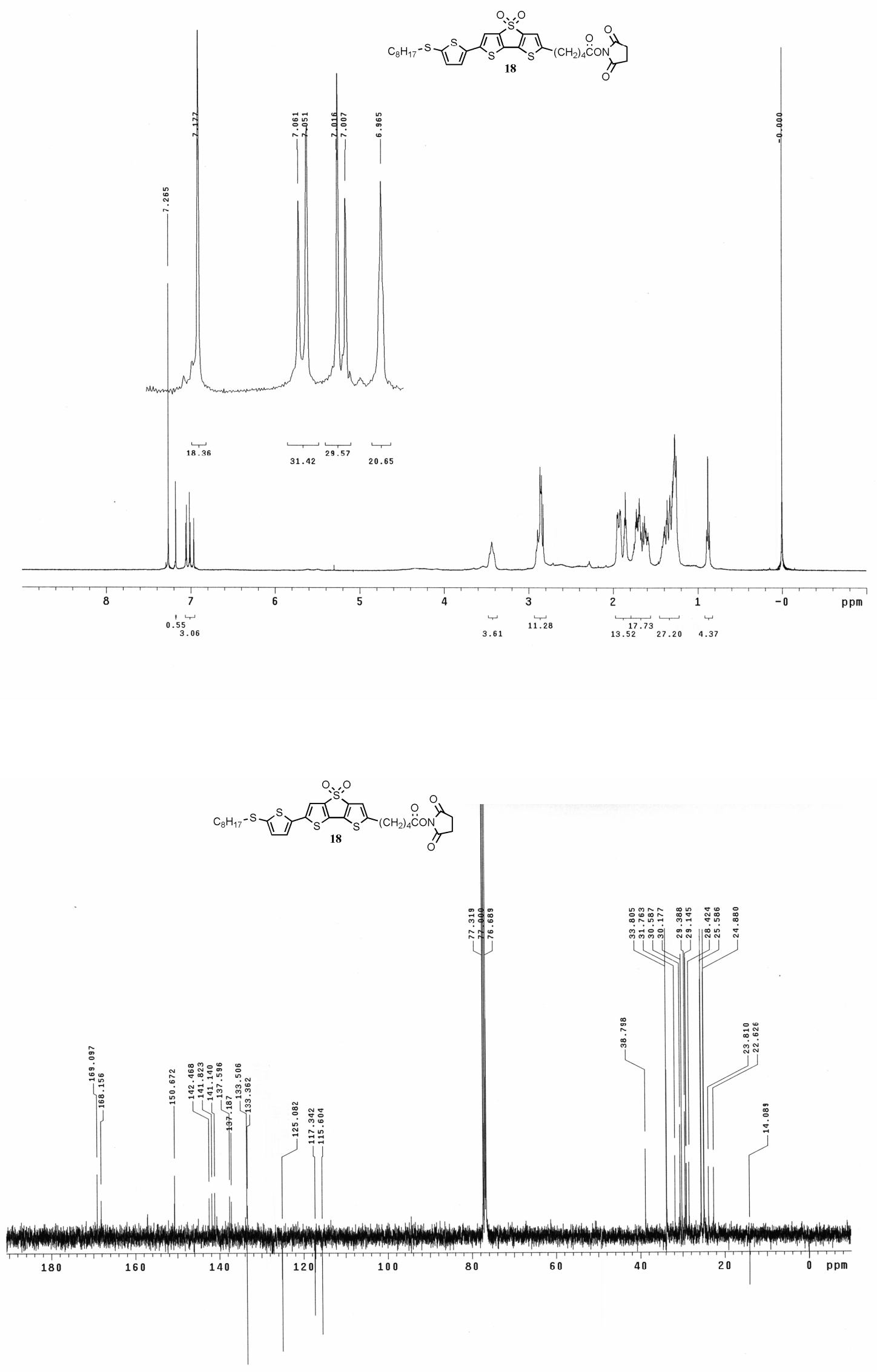

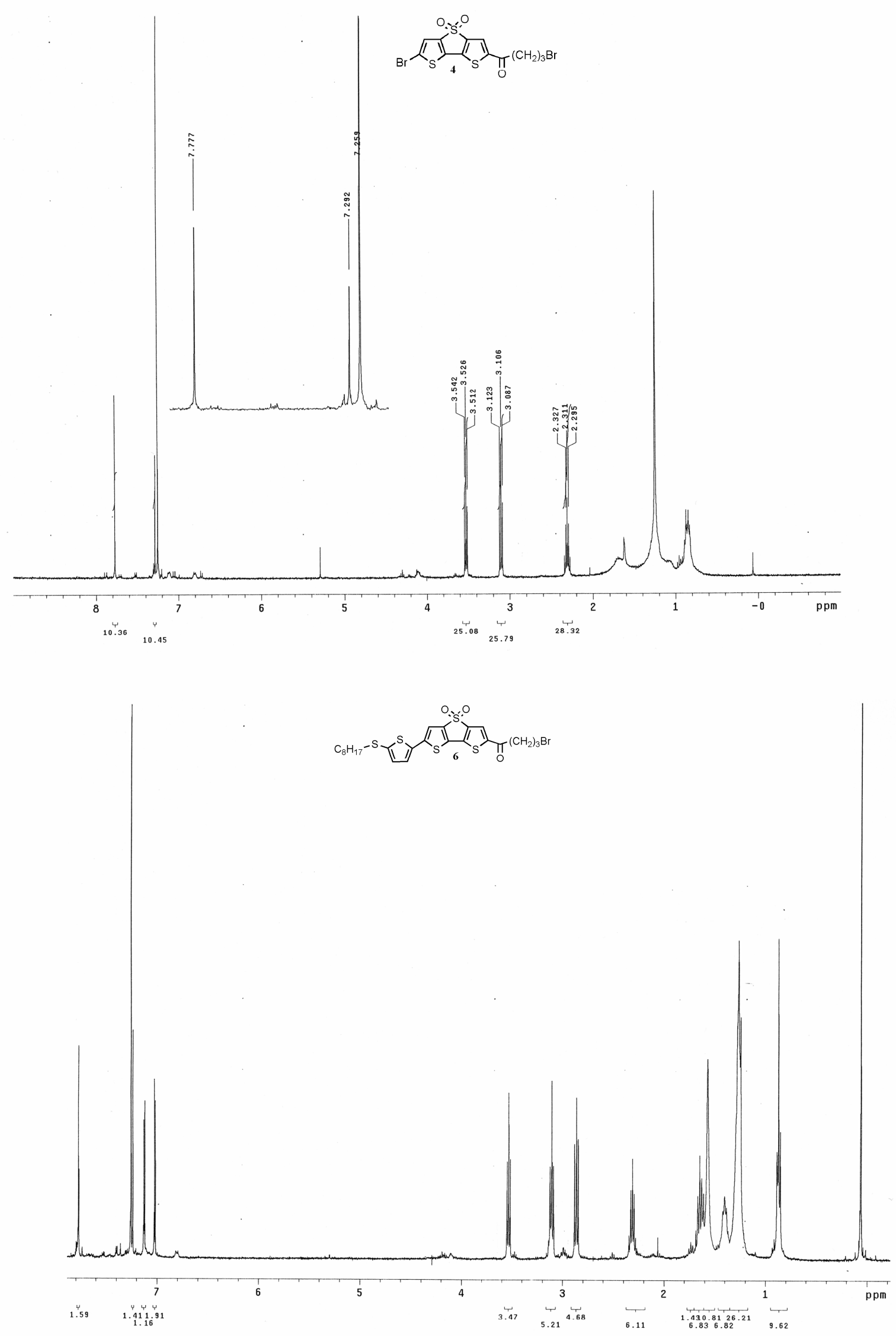

S21 


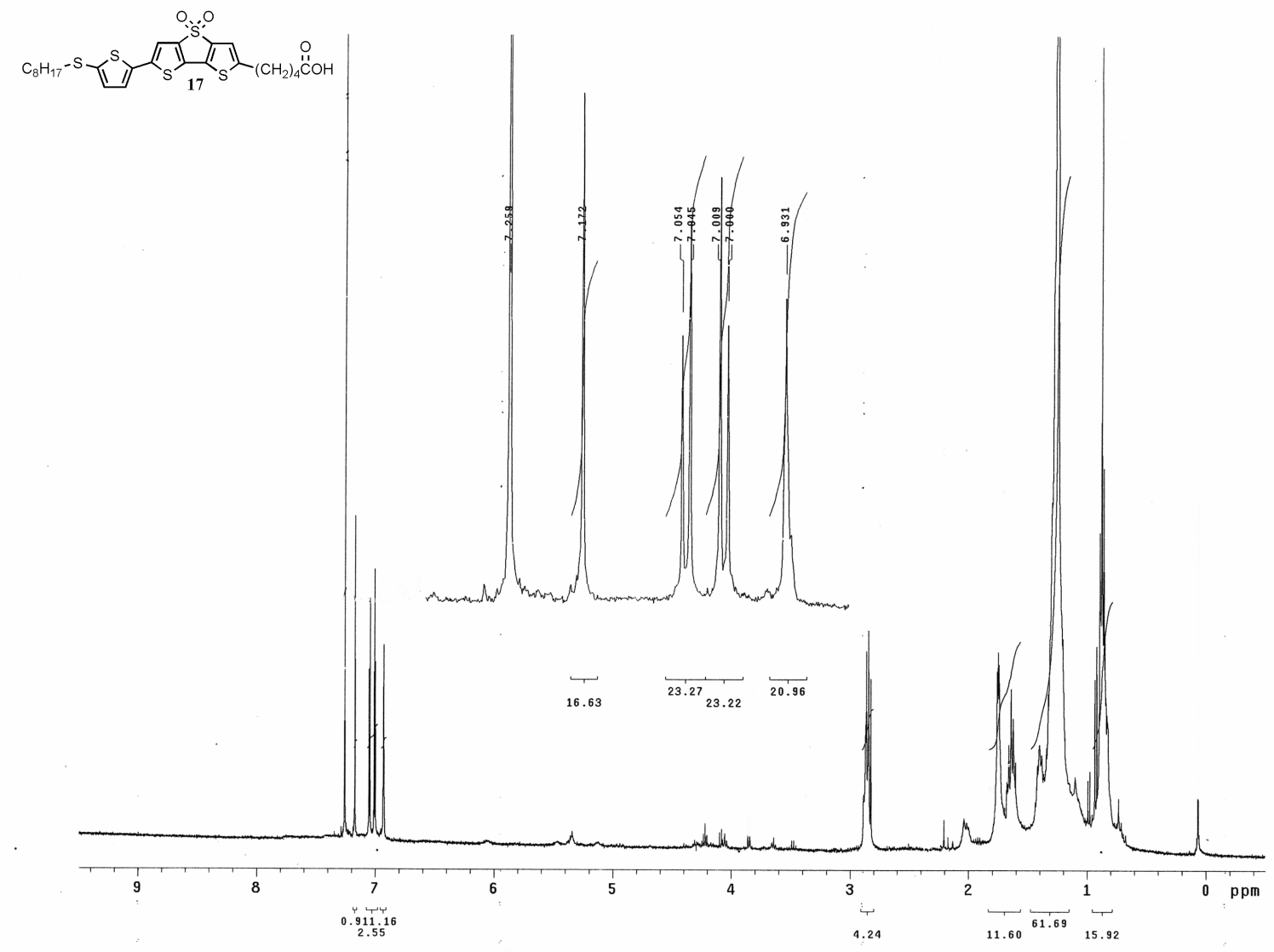

